\title{
Pervasive Computing And Communication Technologies For U-Learning
}

\author{
Young C. Park, Baekseok University, Korea
}

\begin{abstract}
The development of digital information transfer, storage and communication methods influences a significant effect on education. The assimilation of pervasive computing and communication technologies marks another great step forward, with Ubiquitous Learning (U-learning) emerging for next generation learners. In the evolutionary view the $5 G$ (or beyond $4 G$ ) wireless mobile systems will be capable of supporting wwww allowing a highly flexible network and will be able to solve the data traffic and wireless spectrum problems for $U$-learning in the near future.
\end{abstract}

Keywords: Pervasive Computing; 5G; Next Generation Learners; Mobile Network; U- Learning

\section{INTRODUCTION}

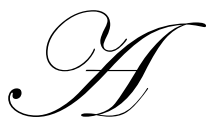

s new technologies evolve and more pervasive forms of technology emerge, computers will become 'invisible' and will be embedded in all aspects of our life. They will be seamlessly integrated into our world in a phenomenon referred to as calm technology. The concept of pervasive computing and U-learning goes beyond portable computers. According to the Chronicle of Higher Education [17], eighty-seven percent of college students in America now own laptops, and fifty-five have smartphones that provide access to the Internet as well as take calls. The number of smartphone users stands at 26.72 million, 50.8 percent of all 52.55 million mobile subscribers and the number of the 4th generation (4G) Long Term Evolution (LTE) subscribers in Korea has surpassed 4 million on April, 2012 [15]. It looks like many students will soon have a three screen day where they bring smartphones to school, use tabs or laptops, and occasionally work on a big screen or interactive whiteboard [2]. Right now, universities and corporate offices are still divided along generational lines, split between what Marc Prensky calls "Digital Natives" and "Digital Immigrants." Where Net Gens do find power is on the Internet because it depends upon a distributed, or shared, delivery system rather than a hierarchal one. This distributed, or shared, power is at the heart of the culture of interaction [13].

The Net Gen needs for learning demand and so the new media enables a shift from traditional broadcast learning to Interactive Learning. It is a major issue in education to build blocks of innovative learning model and to teach Net Gen and prepare them for the 21st century. Sakamura and Koshizuka studied ubiquitous computing technologies for $\mathrm{u}$ learning and a digital ubiquitous museum example [14].

Nakashima et al. presented the latest developments in the burgeoning research area of ambient intelligence and smart environments including pervasive computing and ubiquitous computing [12]. Leonidis et al. proposes an integrated architecture for pervasive computing environments, named ClassMATE (Classroom Multiplatform Augmented Technology Environment), which aims to transform the conventional classroom into a context aware AmI (Ambient Intelligence) environment [11]

In this paper we intend to describe the recent state of the art in the area of pervasive and ubiquitous computing and pervasive learning environments for next generation education. We analyze the characteristics of NET Gen and in order to estimate the Internet traffic generated by Net Gen students in Korea, survey research methods were used for this study. And we propose 5G Networks supporting pervasive learning for Net Gens. 


\section{G NETWORK FOR PERVASIVE LEARNING}

As of September 2012, 87\% of the population aged in Korea are 'wireless Internet users' who have used Wireless Internet services such as mobile network (2G/3G), wireless LAN, WiBro, LTE (long-term evolution) by wireless devices such as smart phones and laptop computers. Wireless Internet usage rate has continued its increase, year 2012 by $21.8 \%$ compared to $65.2 \%$ of 2011 (Fig. 1: KISA, Changes in Wireless Internet Usage Rate in Korea).

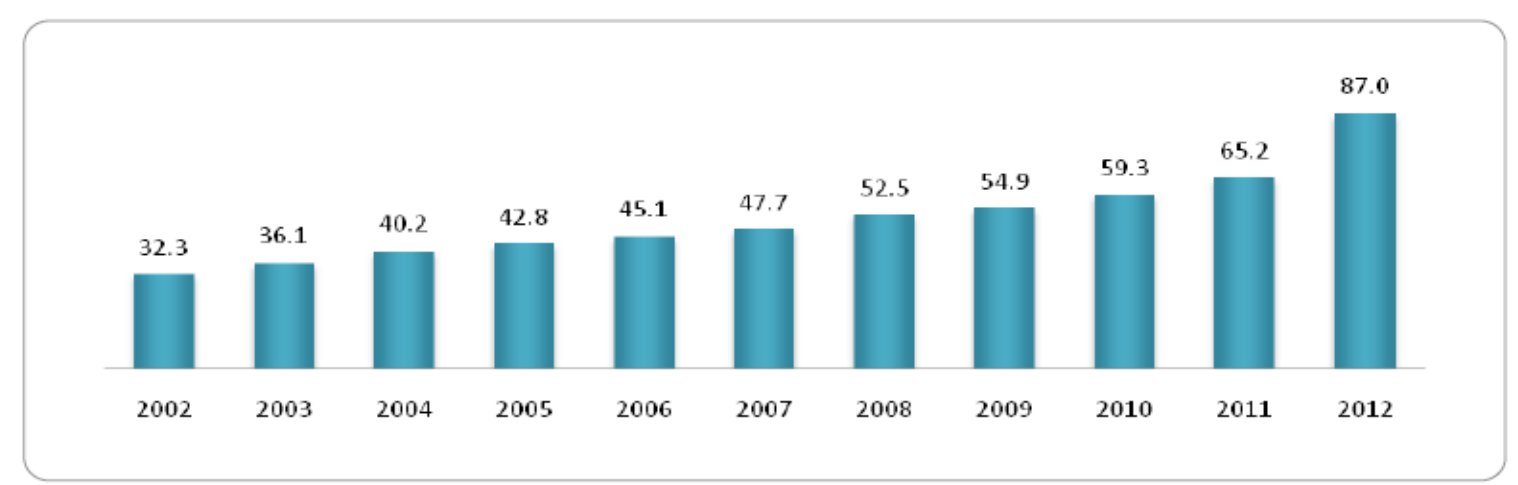

Figure 1. Changes in Wireless Internet Usage Rate in Korea

Among 'College or graduate students' $99.7 \%$ are Wireless Internet users and usage rate for Wireless Internet of 'High school students' are $95.9 \%$. And the primary access method for Wireless Internet is ' $3 \mathrm{G}$ Mobile communication network, while $76.3 \%$ use 'Wireless LAN (WiFi)'. 97 percent of Net Gen own a computer, and 94 percent own a cell phone and 75 percent do schoolwork while instant messaging [9]. In order to meet the complex demands of these Net Gen students, one of the latest trends in education is in the form of media-rich pervasive learning. Pervasive learning facilitated by mobile technologies offers flexibility to learners in terms of community, autonomy, locationality and relationality [16]. Pervasive learning environments with next generation communication technology can have the potential to meet the needs of the Net Gen.

In theory, LTE can support download speeds of up to 100Mbps and upload speeds of up to 50Mbps. In practice users will never see these speeds, but in general 4G LTE is faster than $3 \mathrm{G}$ technologies and the quality of a 4G connection depends on the smartphone, carrier, and location. In general, though, 4G LTE should offer speeds of $5 \mathrm{Mbps}$ to $12 \mathrm{Mbps}$ [8]. Is that data speed enough for u learning using tablets and smartphones in the next decade? In order to estimate the internet traffic generated by Net Gen students in college, survey research methods were used for this study. Two surveys were conducted in spring semester of 2011 and 2012, respectively, in Korea: Number of college students 500, Data collection face-to-face interview and online communication, fieldwork period ( 2 times) Mar. 1 - Jun. 30, 2011 and Mar. 1 - Jun. 30, 2012, sampling method multi-stage stratified cluster sampling. According to survey, the main purposes of using the Internet are 'Getting information or data (92.0\%)', 'Communicating via e-mail or messenger (87.9\%)', 'Leisure activities such as music and game (87.9\%)', 'Internet shopping and selling (58.4\%)' or 'Education and learning (50.6\%)' account for over 50\%. The results showed Net Gen students are relying on Internet for accessing general information. Survey participants were asked how many minutes on an average day spent using the Internet. The Internet usage was identified as email, information retrieval, information sending, and conversation. Respondents indicated that they spent a substantial amount of time, average 194.8 minutes each day, using the Internet. As shown in Table 1, the most frequently used Internet service was information retrieval, followed by watching TV/Video, Email, file transfer, and conversation, respectively. It is important to note that watching TV/Video including online game took second place percentage. 
Table 1. Daily usage of Internet services in 2012 (Unit: minutes per day)

\begin{tabular}{|l|c|c|c|c|}
\hline \multicolumn{1}{|c|}{ Services } & Mean & Minimum & Maximum & \% \\
\hline Email & 33.6 & 12 & 237 & 17.3 \\
\hline Information retrieval & 73.2 & 10 & 221 & 37.6 \\
\hline Watching TV/Video/Game & 47.4 & 7 & 126 & 24.3 \\
\hline File transfer & 21.9 & 2 & 74 & 11.2 \\
\hline Conversation & 18.7 & 1 & 98 & 9.6 \\
\hline Total & 194.8 & - & - & 100 \\
\hline
\end{tabular}

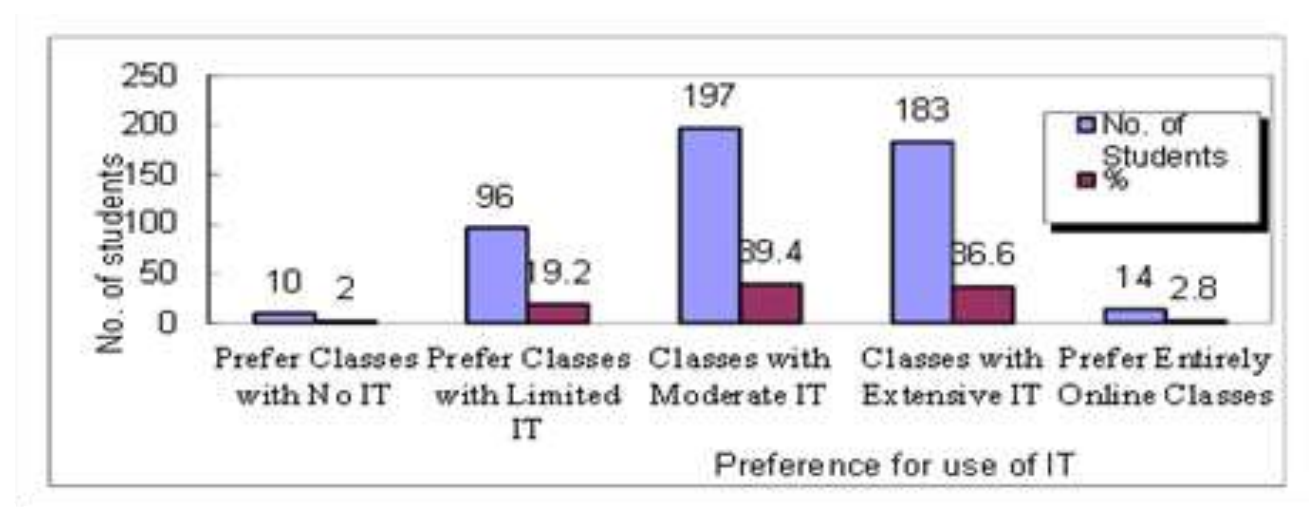

Figure 2. Students preference for use of IT in classes $(\mathrm{N}=500)$

As of June 2012, $88 \%$ of survey participants have a smartphone, $99.2 \%$ have a desktop computer, $60 \%$ have laptop, and $18 \%$ own a tablet computer. This is a significant increase of smartphone ownership compared to June 2011 when only $71 \%$ of survey participants have a smartphone. Another survey was conducted in order to evaluate students' preferences for use of IT in classes. The following factors were considered in evaluating preferences: Previous experience with the use of technology in the classroom, Faculty skill using technology, Hours students use technology, Perceived levels of skill using computers by the respondents, Institution, Major and GPA. We expected to find that the Net Gen student prefers classes that use IT technology. Figure 2 shows a curve with preference for a moderate use of technology in the classroom. The mean value 3.21 and median value 3.12 and mode 3 were squarely at the moderate level of preference for technology use on a scale of 1 to 5 , with 1 being 'I do not prefer the use of technology' to 5 being 'I prefer taking courses that are taken totally online.' We found that 39.4 percent of the students preferred taking courses that use moderate levels of technology, 36.6 percent of the students preferred taking courses that use extensive levels of technology and 2.8 percent preferred taking courses that are delivered entirely online. We can say about 79 percent of participants have positive mind for use IT in classes. In order to determine what size is required for data communication to be adequate for pervasive learning, we conducted another survey. The AT\&T calculator helps calculate how much service is needed based on expected utilization [3]. According to the survey, major generators of traffic by students are desktop computers and smartphones. Survey results are shown in [5]. It is important to note that heavier users use average $7.2 \mathrm{~Gb}$ data traffic per month by desktop computer and average $3.2 \mathrm{~Gb}$ data traffic per month by smartphone. They use totally $10.4 \mathrm{~Gb}$ per month by high-end devices and prefer to search the Internet for more interactive materials, online videos or podcasts, and visual learning. For Net Gen, video is almost 50\% of the Internet traffic and it is expected to reach $90 \%$ by 2014 . These data are consistent with reports in UMTS forum Report 44. Mobile video has grown by 5000\% in last 3 years. Existing 4G network may support the heavier users' data traffic now. But the data traffic will increase nearly 1000 folds by 2015. With the rapid pace of change in the wireless industry, current 4G technology alone will be inadequate in just five years [5]. According to Ericsson traffic and market report on June 2012, mobile data traffic is expected to grow with a CAGR (compound annual growth rate) of around 60 percent (2011-2017), driven mainly by video. This entails growth of around 15 times by the end of 2017 [6]. Future 5G networks could have download speeds that are 1,000 times faster than $4 \mathrm{G}$. The second issue is wireless spectrum which is the invisible infrastructure over which all wireless transmissions travel. The iPhone, for instance, uses 24 times as much spectrum 
as an old-fashioned cell phone, and the iPad uses 122 times as much, according to the Federal FCC (Federal Communications Commission) [7].

Pervasive computing involves three converging areas of ICT (information and communication technology): computing ('devices'), communications ('connectivity') and 'user interfaces'. The 5G family of ITU standards could be implemented around the year 2020. The major difference between current generations and next generation 5G techniques must be something else than increased maximum throughput and some features of $5 \mathrm{G}$ technology are as follows [1]: 1) Data Bandwidth: 1 Gbps and higher 2) Multiplexing: CDMA (code division multiple access) 3) Switching: All packet 4) Core Network: Internet based on IPv6 address 5) The 5G technology network offering enhanced and available connectivity just about the world. $3 \mathrm{G}$ used spectrum up to $5 \mathrm{MHz}$, and $4 \mathrm{G}$ up to $40 \mathrm{MHz}$. The millimeter-wave spectrum is found between 3 and $300 \mathrm{GHz}$, so it has plenty of room to grow. And beyond speed, $5 \mathrm{G}$ could additionally become much more reliable than $4 \mathrm{G}$ networks, thanks to the spectrum's ability to "handle 50 to 100 times more traffic." [4].

Future networks such as 5G will need to be deployed much more densely than today's networks and, due to both economic constraints and the availability of sites, will need to become significantly more heterogeneous than today. One way to achieve that is to "densify" networks to provide more capacity by adding small cell sites, a core focus of HetNets. This can include the use of multiple picocells, that is, small cellular base stations that cover targeted areas, in a broader mobile coverage zone. The 5G network using HetNet supports multiuser virtual environments and pervasive computing which will allow learners to move beyond the desktop and to get immersive environments that enhance learning [10]. U-learning based on 5G technology is right to fit Net Gen's learning needs and desires in the future.

\section{CONCLUSIONS}

In a developmental education classroom, personalized learning and accelerated course completion is transformative. Using ICT technology to deliver accelerated learning models has emerged as a promising strategy for Net Gen students who rely heavily on communications technologies to access information. This growing trend toward ubiquitous computing or pervasive computing using the power of networks has opened the door for learners and instructors to access the world's knowledge from almost anywhere and at any time.

In this paper, we conducted two surveys in spring semester of 2011 and 2012, respectively, to estimate the Internet traffic generated by Net Gen college students in Korea. Current 4G network can support the data traffic of current heavier users among Net Gens, but the data traffic will increase nearly 1000 folds in the next few years which will result in overloading. It is expected to grow that aggregate smartphone traffic in 2016 will be 50 times greater than it is today. The inevitable inclusion of next generation 5G mobile network using HetNet will help to support U- learning for the Net Gen in the future. $5 \mathrm{G}$ network using pervasive computing technologies is able to solve the data traffic and wireless spectrum problems and support the U-learning in the near future.

\section{AUTHOR INFORMATION}

Young Park, Ph.D., was a head of military communication system department in ADD, Korea from 1976 to 2000. Since 2001 he has been with Baekseok University, Korea. He was a visiting professor at Harvey Mudd College, California, in 2012.

\section{REFERENCES}

1. Akhtar, Shakil (2008). 2G-5G Networks: Evolution of Technologies, Standards, and Deployment, Aug., 2008.

2. Ark, Tom Vander (2012), A Turning Point, Huffpost Education, Feb., 21, 2012

3. AT\&T (2012), Data calculator, http://www.att.com/standalone/data-calculator.

4. Churchill, Sam (2012), Millimeter frequencies proposed for 5G, daily wireless.org, Jul., 2012

5. Young C. Park (2013), Educating the Net Gen with pervasive learning, The Clute International Academic Conference, Breckenridge, Colorado, 2013, pp 5 11. 
6. $\quad$ Ericsson (2012), Ericsson traffic and market report, Jun., 2012

7. Goldman, David (2012), The spectrum crunch, Sorry, America: Your wireless airwaves are full, CNN Money Tech, Feb., 21, 2012.

8. Hill, Simon (2012), What you can expect from 4G LTE coverage, The Christian Science Monitor, Sept., 2012.

9. Howe, Neil and Strauss, William (2000), Millennials Rising: The Next Greatest Generation, NewYork, Vintage Books, 2000.

10. Hu, Rose Qingyang et al. (2011), Cooperative, Green and Mobile Heterogeneous Wireless Networks, IEEE 802. 16x, Future Wireless Networks, Mar., 2011.

11. Leonidis, Asterios and Margetis, George and Antona, Margherita and Stephanidis, Constantine (2010), ClassMATE: Enabling Ambient Intelligence in the Classroom, World Academy of Science, Engineering and Technology 2010, pp. 581-584.

12. Nakashima, Hideyuki and Aghajan, Hamid Augusto , and Carlos, Juan (2010), Handbook of Ambient Intelligence and Smart Environments, Springer, 2010.

13. Prensky, Marc (2001), Digital Natives, Digital Immigrants, On the Horizon, MCB University Press, Vol. 9 No. 5, October 2001.

14. Sakamura, Ken and Koshizuka, Noboru (2005), Ubiquitous computing technologies for U Learning, 2005 IEEE International Workshop on Wireless and Mobile Technologies in Education (WMTE’05), pp.11-20, 2005.

15. The Chosunilbo (2012), The 4th generation LTE subscribers in Korea, May 15, 2012.

16. Thomas, Siobhan (2005), Pervasive, persuasive eLearning: modeling the pervasive learning space, Proceedings of the 3rd Int'l Conf. on Pervasive Computing and Communications Workshops (PerCom 2005 Workshops), pp. 332-336.

17. Young, Jeffrey R. (2012), Campuses Look to Digital Tools for Savings, and Reinvention, Almanac of Higher Education 2012, the Chronicle of Higher Education. 
NOTES 